\title{
UMA BREVE DISCUSSÃO DO PAPEL DA GESTÃO INTEGRADA DOS RESIDUOS DE CONSTRUÇÃO E DEMOLIÇÃO (RCD) PARA TRANSFORMÁ-LOS EM RECURSOS ${ }^{1}$
}

\author{
Lidiane Aparecida Alves*, Bruna Santos Romio*, Adriano Reis de Paula e Silva ${ }^{* * *} \&$ Geisiane Rodrigues \\ dos Santos ${ }^{* * * *}$ \\ *Doutoranda pelo Instituto de Geografia da Universidade Federal de Uberlândia - Uberlândia/MG/Brasil - E-mail: lidianeaa@yahoo.com.br \\ ${ }^{*}$ Graduanda da Universidade do Estado de Minas Gerais - Campus Frutal - Frutal/MG/Brasil - E-mail: brunaromio@gmail.com \\ ${ }^{* * *}$ Professor da Universidade do Estado de Minas Gerais - Campus Frutal - Frutal/MG/Brasil - E-mail: prof.eng_adrianoreis@yahoo.com.br \\ ${ }^{* * * *}$ Professora Universidade do Estado de Minas Gerais - Campus Frutal - Frutal/MG/Brasil - E-mail: geisianers@bol.com.br
}

Recebido em 12/2014. Aceito para publicação em 08/2015.

Versão online publicada em 13/01/2016 (http://seer.ufrgs.br/paraonde)

\begin{abstract}
Resumo: Com o crescimento da população, especialmente em áreas urbanas, o volume de resíduos sólidos se tornou um problema para a sociedade contemporânea, que ainda carece de serviços de gerenciamento do descarte dos resíduos sólidos em muitas cidades. Considerando a expansão das cidades, quer por demolições em processo de renovação urbana, ou por edificações novas, é significativo o aumento do volume dos resíduos de construção e demolição (RCD). Popularmente chamados de entulhos, tais resíduos podem acarretar problemas socioambientais caso não recebam um tratamento adequado. A Resolução CONAMA N³07/02 deu início a uma série de atividades envolvendo a valorização dos RCD, pelo incentivo à reutilização, reciclagem e responsabilização dos geradores em relação à elaboração de programas de gerenciamento dos RCD. 0 objetivo do presente artigo foi tecer considerações sobre o gerenciamento dos resíduos sólidos, nomeadamente RCD, considerando os principais instrumentos normativos que versam sobre a questão, especialmente a resolução CONAMA. Para tanto, foi realizado um levantamento bibliográfico para análise da temática. Conclui-se que a aplicação da metodologia de gerenciamento dos RCD pode proporcionar benefícios econômicos, sociais e ambientais significativos. Destaca-se que o surgimento dos instrumentos normativos legais, no âmbito das diferentes escalas administrativas, da federal à municipal, é um primeiro passo para o advento de uma nova postura em relação aos RCD, que, majoritariamente, devem ser tratados como recursos e não como "lixo". Palavras-chave: Resíduos sólidos. Resíduos de construção e demolição. Gestão.
\end{abstract}

\section{Introdução}

Com o crescimento da população, concentrada, sobretudo nas cidades, o volume de resíduos sólidos se tornou um problema, especialmente se levado em consideração que muitas cidades que ainda carecem de serviços de gerenciamento do descarte de tais resíduos. A ausência ou mesmo a ineficiência no gerenciamento dos resíduos gerados pela população, além de provocar gastos financeiros significativos, pode acarretar graves danos ao meio ambiente e comprometer a saúde e o bem-estar da população. As recentes normas brasileiras orientam a prática de redução e reciclagem dos resíduos, com vistas a facilitar o descarte correto e disciplinar os diferentes atores no caminho da gestão sustentável dos resíduos.

Além disso, a expansão das cidades provoca o aumento da geração de Resíduos de Construção e Demolição (RCD), sendo tal demanda potencialmente significativa nos centros urbanos em expansão. Segundo Pinto (1999), uma grande quantidade de resíduos foi gerada nos últimos anos nas áreas urbanizadas, quer por demolições em processo de renovação urbana, ou por edificações novas, em razão do desperdício de materiais ou em consequência da caracterização arquitetônica da construção. A partir de tais circunstâncias conclui-se que a maioria das atividades desenvolvidas no setor da construção civil é geradora de resíduos. Segundo o manual "Manejo e gestão de resíduos da construção civil", os RCD podem alcançar a cifra expressiva de até duas toneladas de entulho para cada tonelada de lixo domiciliar. (PINTO; GONZÁLES 2005).

Com o avanço das construções no país, o descarte irregular dos resíduos de obras e demolição causam poluição e assoreamento dos rios, gerando altos custos para economia e para o meio ambiente. 0 entulho tem características variáveis como areias e britas, pedaços de madeiras, argamassas, metais, concretos, vigas, tijolos, plástico entre outros. Além disso, no processo da construção civil o alto índice de perdas é a principal causa geradora de entulho (resíduos) que corresponde em média a $50 \%$ dos materiais desperdiçado na obra,

${ }^{1} \mathrm{O}$ artigo foi organizado a partir do trabalho de conclusão de curso "LOGÍSTICA REVERSA: ESTUDO DO SISTEMA DE GERENCIAMENTO MUNICIPAL DOS RESÍDUOS DE CONSTRUÇÃO E DEMOLIÇÃO (RCD) EM FRUTAL-MG“, que teve apoio do CNPq, pelo Edital no 05/2013 PIBITI/UEMG/CNPq. 
como afirma Schneider (2003).

Ao se tratar do enfoque no descarte dos resíduos sólidos, de modo geral, há diversas áreas de interesse. Os enfoques econômico, social, ambiental, tecnológico e cultural contribuem no sentido de possibilitar a construção de cenários e apresentar soluções que atendam demandas de diferentes segmentos da sociedade.

Neste contexto, a expressão "lixo" foi substituída por resíduos sólidos, e estes, que antes eram conhecidos como meros subprodutos do sistema produtivo, passaram a ser compreendidos como responsáveis por ocasionar graves problemas de degradação ambiental, quando não 'depositados' corretamente. Além disso, os resíduos sólidos diferenciam-se do termo lixo, porque possuem valor econômico agregado, possibilitando o reaproveitamento oportuno no processo produtivo, enquanto o lixo não possui qualquer tipo de valor, pois se trata tudo aquilo que deve apenas ser descartado, conforme Demajorovic (1995).

Por esta perspectiva, observa-se que os resíduos gerados deviam ter como destinação prioritária a reutilização (reprocesso), seguida da reciclagem. Uma vez que um resíduo não possa ser reutilizado ou reciclado, deve ser tratado ou disposto em local adequado previsto pela legislação. Os resíduos sólidos são definidos pela NBR 10.004 (ABNT) como:

[...] resíduos nos estados sólidos e semissólidos, que resultam de atividades da comunidade de origem: industrial, doméstica, hospitalar, comercial, agrícola, de serviços e de varrição. Ficam incluídos também nesta definição os lodos provenientes de sistemas de tratamento de água, aqueles gerados em equipamentos e instalações de controle de poluição, bem como determinados líquidos cujas particularidades tornem inviável o seu lançamento na rede pública de esgotos ou corpos de água $(2004$, p.1).

De acordo com Pereira et alii (2013), os resíduos sólidos podem ser classificados quanto à origem, composição química, presença de umidade e, por fim, quanto à toxicidade. A) quanto à origem: domiciliar; comercial; público; hospitalar; industrial; agrícola; engenharia e construção civil; B) Quanto à composição química: orgânico e inorgânico; C) quanto à presença de umidade: seco e úmido; D) quanto à toxicidade: classe I - perigosos e classe II - não perigosos.

Ao considerar a classificação com base na origem, tem-se que:

[...] urbanos: que fazem parte dessa classificação os resíduos residenciais, comerciais, de varrição, feiras livres, capinação e poda; industriais: que são resíduos advindos de indústrias, nos quais se incluem um grande percentual de lodos provenientes dos processos de tratamentos de efluentes líquidos; serviços de saúde: que abrangem os resíduos sólidos hospitalares, de clínicas médicas e veterinárias, postos de saúde, consultórios odontológicos e farmácias; radioativos: em que se incluem os resíduos de origem atômica sobtutela do Conselho $\mathrm{Na}$ cional de Energia Nuclear (CNEN;) e resíduos agrícolas: neles se agrupam os resíduos resultantes de processos agropecuários com ênfase em embalagens de defensivos agrícolas, pesticidas, herbicidas e fungicidas (NAIME, SPILKI, 2012, p.121).

Para os resíduos oriundos das atividades da indústria e da construção civil, há uma resolução específica. A Resolução 307, de cinco de julho de 2002, do Conselho Nacional do Meio Ambiente - CONAMA define claramente que os resíduos da construção civil "são provenientes de construções, reformas, reparos e demolições de obras de construção civil, e os resultantes da preparação e da escavação de terrenos, tais como: tijolos, blocos cerâmicos, concreto em geral, solos, rochas, metais, resinas, colas, tintas, madeiras e compensados, forros, argamassa, entre outros, comumente chamados de entulhos de obras, caliça ou metralha" (307/CONAMA).

Os resíduos também podem ser classificados de acordo com sua natureza, avaliando seu grau de degradabilidade como facilmente degradáveis: matéria orgânica, que é o constituindo principal de resíduos sólidos de origem urbana; moderadamente degradáveis: são papéis, papelão e material celulósico, atualmente existe um amplo mercado que fazem a reciclagem desses materiais, então praticamente todo material dessa natureza é reciclado; dificilmente degradáveis: são resíduos têxteis, aparas e serragens de couro, borracha e madeira, que hoje também são parcialmente reaproveitados; não degradáveis: incluem vidros, metais, plásticos, pedras, terra e outros (NAIME, SPIKLKI, 2012).

Portanto, a partir da conjuntura apresentada, o objetivo deste artigo é tecer considerações sobre o gerenciamento dos resíduos sólidos, nomeadamente os resíduos de construção e demolição (RCD), considerando os principais instrumentos normativos que versam sobre a questão.

\section{A problemática da destinação dos resíduos sóli- dos}

Como observa Castilhos (2003), as grandes quantidades de resíduos sólidos gerados em áreas urbanas e a forma como eles vêm sendo tratados e descartados, pela sociedade moderna, tem sido objeto de preocupações e estudo de diversos pesquisadores. A destinação final inadequada dos resíduos sólidos tem consequências negativas para o meio ambiente e para a saúde da população. 0 autor fundamenta que a preservação do meio ambiente e o uso sustentável dos recursos naturais revestem-se da importância significativa para 
a sobrevivência e a qualidade de vida das gerações atuais e futuras. E que a busca de soluções para a destinação final dos resíduos tem se constituído em um grande desafio, sobretudo, no que concerne à poluição dos solos, do ar e dos recursos hídricos.

Quando se fala de destinação de resíduos é indiscutível a importância do conceito da hierarquia do gerenciamento de resíduos sólidos, na produção e ao longo do ciclo de vida do produto, ou seja, da geração à destinação final dos resíduos, onde são considerados: minimização da quantidade de resíduos gerados, reutilização, reciclagem e destinação final adequada, conforme colocado por Fernandes (2009), que destaca também o papel dos sete Princípios Gerais da Gestão

\section{Princípios Gerais da Gestão de Resíduos}

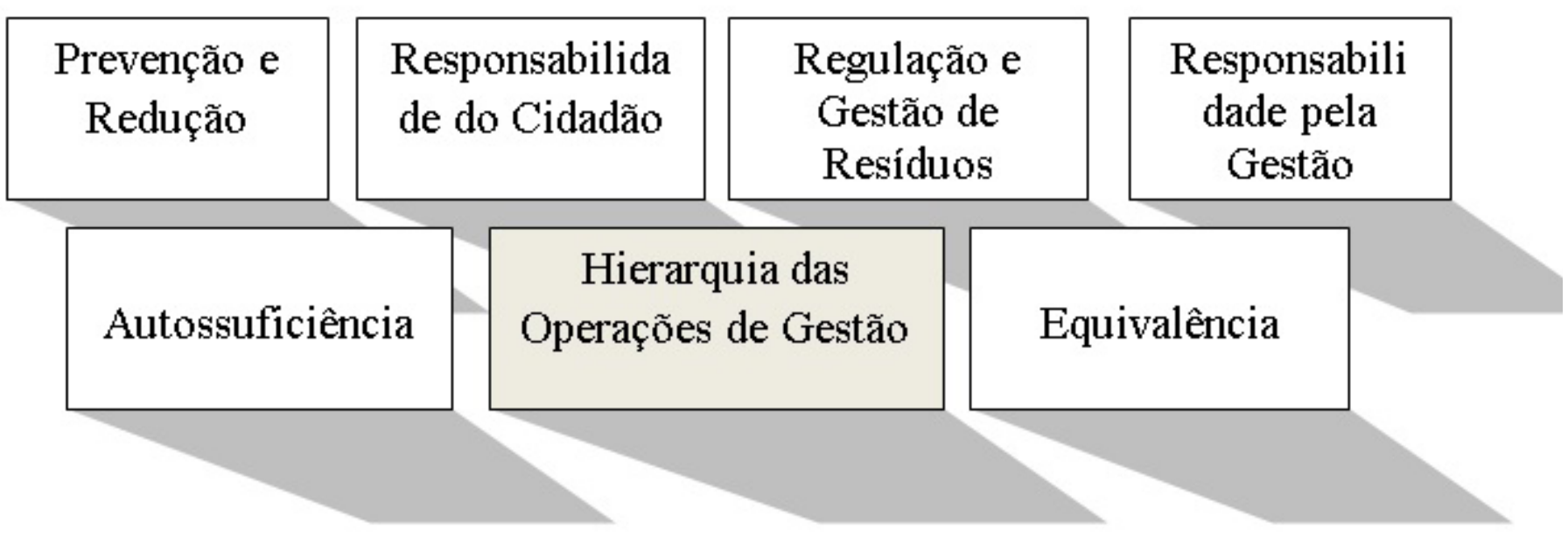

Fonte: Adaptado de Fernandes (2009).

de Resíduos, conforme representado na figura 1.

No Brasil, segundo Jacobi (2006) desde 1989 multiplicam-se as experiências de gestão compartilhada de resíduos sólidos através de programas municipais de coleta seletiva - muitos em parceria com catadores de materiais recicláveis organizados em associações e cooperativas. Trata-se de experiências que devem ser valorizadas apesar de sua pequena escala, porque geram benefício econômico, ambiental e social. A coleta seletiva reduz o lixo na fonte geradora, o reaproveitamento e a reciclagem de matérias-primas, a geração de renda, e inclusão social, assim como também minimiza o impacto ambiental causado pelo aterramento dos resíduos.

A reutilização dos resíduos é uma simples movimentação de materiais de uma aplicação para outra. A reciclagem dos resíduos consiste na transformação destes resíduos em novos produtos. Uma alternativa viável é a incineração dos resíduos podendo extrair energia dos materiais, e em último caso, quando não há mais o que se aproveitar dos resíduos pode ser feito o aterramento.

Considerando a destinação final, a deliberação normativa do COPAM (2008) a respeito da destinação final de resíduos urbanos relaciona algumas das áreas per- mitidas e não permitidas para descarte de resíduos urbanos. A) Área de Preservação Permanente (APP): área protegida coberta ou não por vegetação nativa, com a função ambiental de preservar os recursos hídricos, a equilíbrio geológico, a biodiversidade, o fluxo gênico de fauna e flora, proteger o solo e assegurar o bem-estar das populações humanas. B) Lixão: forma inadequada de disposição final de resíduos sólidos, caracterizada pela sua descarga sobre o solo, sem critérios técnicos e medidas de proteção ambiental ou à saúde pública. C) Aterro Controlado: processo de disposição de resíduos sólidos urbanos no solo, sem causar danos ou riscos à saúde publica e à segurança, minorando os impactos ambientais. D) Depósito de Lixo: denominação genérica do local utilizado para destinação final de resíduos sólidos urbanos (RSU) coletados pela municipalidade, que dependendo da técnica ou forma de implantação e operação pode ser classificado como: aterro sanitário, aterro controlado, lixão ou outra técnica pertinente. E) Aterro Sanitário: processo adequado de disposição de resíduos sólidos urbanos no solo sem causar danos à saúde publica e à segurança, minimizando os impactos ambientais (PEREIRA et alii, 2013). Também são descritos os princípios de engenharia utilizados para confinar os resíduos sólidos à menor área possível e 
reduzi-los ao menor volume permissível, cobrindo-os com uma camada de terra na conclusão de cada jornada de trabalho. São alojados em área geologicamente apropriadas, distantes de rios ou fontes de água.

A análise dos dados da Pesquisa Nacional de Saneamento Básico (PNSB), realizada pelo Instituto Brasileiro de Geografia e Estatística (IBGE), que teve como referência o ano de 2008, mostrou que em 1989 , 1,1\% dos resíduos sólidos do Brasil eram descartados em aterro sanitário. Entre 2000 e 2008, o percentual passou de $17,3 \%$ para $27,7 \%$ (IBGE, 2010). Os resíduos que seguiam para vazadouro a céu aberto, passaram de $72,3 \%$ para $50,8 \%$ em 2008. A situação dos resíduos direcionados a aterro controlado passou de 9,6\% em 1989 para 22,5\% em 2008.

Contudo, pode-se considerar que a maioria dos resíduos sólidos municipais coletados nas cidades brasileiras não recebe destinação final adequada, sendo despejadas em lixões, nos quais não há qualquer espécie de tratamento inibidor ou redutor dos efeitos poluidores. No Brasil, os aterros estão dispostos de forma desigual, pois há uma grande zona na região norte sem nenhuma forma de disposição de resíduos urbanos adequada.

Tendo em vista que as exigências dos órgãos ambientais têm ficado cada vez mais rigorosas e restritivas, muitos centros urbanos, com altos índices de crescimento da população, têm encontrado muitas dificuldades em obter novos locais para instalarem novos depósitos de lixo (aterro). Deste modo, Pinto (2009) conclui que no Brasil apenas 56,8\% dos resíduos sólidos urbanos têm tratamento adequado e que a destinação desses resíduos sólidos representa que, 63\% do descarte são feitos em lixões, $18 \%$ do descarte no aterro controlado, 14\% no aterro sanitário, 5\% N.D. Logo, a reciclagem mostra-se como uma solução viável do ponto de vista econômico, além de ser ambientalmente correta.

No entanto, as melhorias são necessárias não somente na parte do tratamento dos resíduos, mas também nos sistemas de coletas, na disposição preliminar, no tratamento e na destinação final dos resíduos coletados. Para que a reciclagem possa ser adotada de forma mais vigorosa, existe a necessidade de uma conscientização populacional que possibilite a compreensão de uma melhoria generalizada em todo o serviço de coleta de lixo.

É necessário cada organização estabelecer uma política clara de descarte e destinação final dos resíduos sólidos para que cada um dos colaboradores saiba exatamente como proceder em cada ocasião. Tais políticas devem ter fundamentos baseados nos tipo de classificação dos resíduos gerados e que sejam de realização viável. A destinação final dos resíduos tem de ser feita corretamente, conforme mostram Naime, Spilki (2012).

Nessas perspectivas, para o descarte adequado dos resíduos inicialmente se deve realizar a identifica- ção e a tipificação da matéria envolvida e de seu potencial de risco à saúde humana ou ao ambiente. Portanto, em cada processo de descarte os indivíduos devem analisar os seguintes critérios sobre o material a ser dispensado, como por exemplo a composição química do mesmo, qual o risco que o produto causará para a saúde humana e ao ambiente, o possível risco biológico do material, a radioatividade e qual a probabilidade de reaproveitamento e reciclagem do mesmo. De posse dessas informações será possível iniciar o processo de decisão sobre qual o melhor manejo em cada caso. Em diversos casos, apenas uma dessas características citadas, já define qual o descarte mais adequado para aquele produto, segundo afirmam Naime, Spilki (2012).

Todavia, somente a partir de 1993 a Resolução CONAMA no 5 de 1993, previu a implantação do gerenciamento dos resíduos sólidos obrigatório nacionalmente, a qual manteve o conceito técnico ou definição técnica de resíduos sólidos previstos na NBR 10.004 da ABNT (2004).

No âmbito da gestão dos resíduos sólidos, a classificação de acordo com a ABNT (2004) é fundamental, pois permite ao gerador do resíduo identificar com facilidade o seu potencial de risco, além de identificar as melhores alternativas de tratamento e disposição final do produto.

\section{0 caso dos resíduos de construção e demolição (RCD)}

É consenso entre vários autores que a construção civil é uma das mais importantes atividades para o desenvolvimento econômico e social do país, que, entretanto, comporta-se, ainda, como grande geradora de impactos ambientais, quer seja pelo consumo de recursos naturais, quer pela modificação da paisagem ou pela geração de resíduos.

O estudo dos resíduos da construção civil é importante devido ao desconhecimento dos volumes gerados, dos impactos que os mesmo causam, dos custos sociais envolvidos e, inclusive, das possibilidades de seu reaproveitamento, que traz benefícios financeiros, institucionais e ambientais (PALERMO, 2006).

De acordo com Jonh (2000), estes resíduos, conhecidos como resíduos da construção civil (RCC), ou os resíduos de construção e demolição (RCD), são originários da execução de projetos de infraestrutura (obras e serviços públicos), construção urbana, demolição e reformas das construções já existentes, e integram os resíduos sólidos urbanos. Esses podem representar até $50 \%$ do total de resíduos sólidos produzidos nas grandes cidades, por meio de diversos agentes, como empresas construtoras, incorporadores imobiliários, empresas de pequeno e médio porte prestadoras de serviços de engenharia, órgãos públicos e empreiteiros de obra. Portanto, esses resíduos são produzidos por pequenos, médios e grandes geradores como mostram Ângulo et alii. (1999). 
Segundo Santos (2007) os RCD’s são extremamente heterogêneos e basicamente compostos por concretos, argamassas e rochas que, a princípio, apresentam alto potencial de reciclagem; materiais cerâmicos, como blocos, tijolos e lajotas, que também apresentam alto potencial reciclável sem necessidade de técnicas sofisticadas de beneficiamento; solos, argilas, areia, materiais facilmente separados dos outros por meio de peneiramento; asfalto, material com alto potencial de reciclagem em obras viárias; metais ferrosos: utilizados pela indústria metalúrgica; madeiras: material parcialmente reciclável com o agravante de que se impermeabilizadas ou pintadas devem ser consideradas como material poluente e tratadas como resíduos industriais perigosos, em decorrência do risco de contaminação; outros materiais, como papéis, papelão, plásticos e borracha, são passíveis de reciclagem, porém apresentam desvantagens diante dos avanços tecnológicos.

Cabe destacar que os RCD's de novas construções, de acordo com Levy (1997), são oriundos de todas as etapas de execução da obra, ou seja, concretagens, alvenarias, revestimentos e acabamentos. 0 mesmo autor observa que a origem dos RCD se dá em catástrofes naturais ou artificiais (incêndios, desabamentos, bombardeios, entre outros); através de demolições de pavimentos rodoviários de concreto ou de obras que chegaram ao final de sua vida útil e através de deficiência inerentes ao processo construtivo empregado atualmente.

De acordo com Ferreira et alii., 2009, p.13. "os principais resíduos da construção civil e demolição são constituídos de pedras, tijolos/blocos, areia, cimento, argamassa, concreto, madeira, cal e ferro". Segundo a Resolução CONAMA N 307/02,

[...] resíduos da construção civil são os provenientes de construções, reformas, reparos e demolições de obras de construção civil, e os resultantes da preparação e da escavação de terrenos, tais como: tijolos, blocos cerâmicos, concreto em geral, solos, rochas, metais, resinas, colas, tintas, madeiras e compensados, forros, argamassa, gesso, telhas, pavimento asfáltico, vidros, plásticos, tubulações, fiação elétrica, etc., comumente chamados de entulhos de obras, caliça ou metralha (2002, p.4).

Em razão da quantidade e tipos diferenciados de RCD’s, o CONAMA formulou a Resolução № 307/02, que responsabiliza os geradores de resíduos do processo de novas construções, como também de reformas, reparos e demolições de estruturas e rodovias, bem como por aqueles resultantes da remoção de vegetação e escavação de solos por sua destinação final.

A Resolução CONAMA N 307/02 classifica os resíduos oriundos da indústria da construção civil como pertencente à Classe $\mathrm{A}$, os resíduos reutilizáveis ou recicláveis como agregados, tais como: (a) de construção, demolição, reformas e reparos de pavimentação e de outras obras de infraestrutura; (b) de construção, demolição, reformas e reparos de edificações, componentes cerâmicos, argamassa e concreto; (c) de processo de fabricação e/ou demolição de peças pré-moldadas em concreto, produzidas nos canteiros de obras; como pertencentes à classe $\mathrm{B}$, que são os resíduos recicláveis para outras destinações, tais como: plásticos, papel/ papelão, metais, vidros, madeiras e outros; como pertencentes à classe $\mathrm{C}$, que são os resíduos para os quais não foram desenvolvidas tecnologias ou aplicações economicamente viáveis que permitam a sua reciclagem/recuperação; e por fim pertencentes à classe D, que são os resíduos perigosos oriundos do processo de construção, tais como: tintas, solventes, óleos e outros,

Quadro 1: Classes em que deve ser enquadrado o RCD triado

\begin{tabular}{|c|c|c|}
\hline Classe & Integrantes & Destinação \\
\hline A & $\begin{array}{l}\text { resíduos reutilizáveis ou recicláveis } \\
\text { como agregados, tais como componentes } \\
\text { cerâmicos, argamassa, concreto e } \\
\text { outros, inclusive solos }\end{array}$ & $\begin{array}{l}\text { deverão ser reutilizados ou reciclados na } \\
\text { forma de agregados; ou encaminhados a } \\
\text { áreas de aterro de resíduos da } \\
\text { construção civil, onde deverão ser } \\
\text { dispostos de modo a permitir sua posterior } \\
\text { reciclagem ou a futura utilização, para } \\
\text { outros fins da área aterrada }\end{array}$ \\
\hline B & $\begin{array}{l}\text { resíduos recicláveis para outras } \\
\text { destinações, tais como plástico, papel, } \\
\text { papelão, metais, vidros, madeiras e } \\
\text { outros }\end{array}$ & $\begin{array}{l}\text { deverão ser reutilizados, reciclados ou } \\
\text { encaminhados a áreas de armazenamento } \\
\text { temporário, sendo dispostos de modo a } \\
\text { permitir a sua utilização ou reciclagem } \\
\text { futura }\end{array}$ \\
\hline $\mathrm{C}$ & $\begin{array}{l}\text { resíduos para os quais não foram } \\
\text { desenvolvidas tecnologias ou aplicações } \\
\text { economicamente viáveis para a } \\
\text { reciclagem/ recuperação, tais como os } \\
\text { restos de produtos fabricados com gesso }\end{array}$ & $\begin{array}{l}\text { deverão ser armazenados, transportados e } \\
\text { receber destinação adequada em } \\
\text { conformidade com as normas técnicas } \\
\text { especificas }\end{array}$ \\
\hline $\mathrm{D}$ & $\begin{array}{l}\text { resíduos perigosos oriundos da } \\
\text { construção, tais como tintas, solventes, } \\
\text { óleos e outros, como o amianto, ou } \\
\text { aqueles efetiva ou potencialmente } \\
\text { contaminados, oriundos de obras em } \\
\text { clinicas radiológicas, } \\
\text { industriais e outras }\end{array}$ & $\begin{array}{l}\text { deverão ser armazenados, transportados, } \\
\text { reutilizados e receber destinação adequada } \\
\text { em conformidade com a legislação e as } \\
\text { normas técnicas especificas }\end{array}$ \\
\hline
\end{tabular}

Fonte: Adaptado de Pinto e Gonzáles (2005). 
ou aqueles contaminados oriundos de demolições, reformas e reparos de clínicas radiológicas, instalações industriais e outros (CONAMA, 2002).

Esta triagem consiste em uma primeira condição fundamental para a gestão adequada dos RCD's. Logo, a Resolução CONAMA №307/02, deu início a uma série de atividades envolvendo a valorização dos RCD, através do incentivo à reutilização e reciclagem dos mesmos. Além de tratar da valorização dos resíduos, essa resolução também estabelece a responsabilidade dos geradores em relação à elaboração de programas de gerenciamento de resíduos para cada obra. Neste contexto, a implantação de práticas de gerenciamento nos canteiros de obras passa a ser de fundamental importância para o setor da construção civil. A introdução de técnicas, que visem à minimização e o reaproveitamento dos RCD, representa uma possibilidade de reduzir os impactos ambientais produzidos pelo setor.

Afinal, é um equívoco a ausência de uma cultura de reutilização e reciclagem e o desconhecimento da potencialidade do entulho reciclado como material de construção. Isso, para Zordan (1997), são as causas dos grandes volumes de RCD gerados em obras de construção civil.

Os principais impactos sanitários e ambientais relacionados aos RCD's, na opinião de Pinto (1999), são aqueles associados às deposições e disposições ${ }^{2}$ irregulares, sendo uma conjunção de efeitos deteriorante do ambiente local, comprometendo a paisagem, o tráfego de pedestres e de veículos e a drenagem urbana. A disposição em córregos, fundo de vales e terrenos baldios vem gerando também graves problemas aos centros urbanos, tais como a degradação ambiental, de grandes áreas utilizadas como "lixões". 0 problema da disposição irregular dos RCD ainda tem um agravante, pois a legislação federal, Resolução CONAMA N ${ }^{\circ}$ $307 / 02$, proíbe o encaminhamento destes resíduos a aterros sanitários comuns, pois os mesmos contribuem diretamente para o esgotamento dessas áreas que são escassas. Com isso, aumenta a preocupação referente às deposições irregulares deste tipo de resíduo.

Como destaca a Resolução CONAMA N 307/02, neste contexto aumenta a importância da redução, reutilização e reciclagem dos resíduos gerados nos canteiros de obra. Afinal, a redução da geração de resíduos mostra-se como a alternativa mais eficaz para a diminuição do impacto ambiental, além de ser a melhor alternativa do ponto de vista econômico.

Os desperdícios implicam em problemas socioambientais. Durante muitos anos, não houve estimativas das perdas e dos desperdícios de materiais nos processos construtivos. Além disso, não havia informações sobre a natureza das atividades construtivas, da par- ticipação dos diversos agentes na construção das edificações e da origem dos resíduos. Atualmente, o grande volume de entulhos gerados nas construções urbanas evidência a necessidade de novos locais para sua disposição final. São cada vez mais limitadas as áreas destinadas ao descarte, as empresas coletoras e os pequenos geradores muitas vezes não as utilizam, descartando seus resíduos em quaisquer áreas urbanas livres (FIGUEIREDO, 1994).

O desperdício não pode ser visto apenas como materiais não utilizados no canteiro (rejeito), mas também como toda perda efetiva durante o processo construtivo. Portanto, o uso de recursos, além do necessário à execução de determinada etapa, é caracterizado como desperdício e classificado conforme sua origem, natureza e controle (FIGUEIREDO, 1994).

A ampla quantidade de entulho gerada no Brasil mostra que o desperdício de material é um fato relevante e que deve ser pesquisado, analisado e solucionado tanto pelas indústrias da construção civil como por prefeituras, pela própria população e também universidades. Nas obras de reforma, a falta de cultura voltada para a reutilização e reciclagem do material e o desconhecimento da potencialidade do resíduo reciclado, como material de construção pelo meio técnico do setor, são as principais causas da geração de resíduos, portanto, não estão relacionadas ao desperdício, mas sim a não reutilização do material como mostram Mendes et alii. (2004)

Dessa forma, Jacobi (2004) afirma que durante muitos anos, não houve estimativas das perdas e dos desperdícios de materiais nos processos construtivos, mas atualmente, pesquisas mostram que as informações obtidas exibem índices de perdas na construção e de geração de resíduos, os quais tem alta incidência na composição dos resíduos sólidos urbanos.

Segundo o controle, as perdas são consideradas inevitáveis (perdas naturais) ou evitáveis; quanto à natureza, ela pode ocorrer por superprodução, substituição, espera, transporte ou aparecer no processamento como produtos defeituosos, estoques, movimentos de cargas ou acidentes. Conforme sua origem, as perdas podem ocorre no próprio processo produtivo, na produção dos materiais e na preparação de recursos humanos, projetos, planejamentos e suprimentos. Todos os casos relacionam-se à qualificação do trabalhador (COLOMBO, 1999, p. 196 apud NETO, 2005).

Segundo Castilhos (2003), uma das maiores preo-

\footnotetext{
${ }^{2}$ A deposição de resíduos é a atividade intermediária, anterior à destinação final dos resíduos sólidos, sendo quase sempre realizada de forma aleatória e ilegal, também é o processo sedimentar que consiste na acumulação de matéria mineral ou orgânica, transportada pela água, vento ou gelo. Disposição de resíduos sólidos é a atividade intermediaria ou final, com manejo e arranjo corretos dos resíduos, é a prática de dispor os resíduos sólidos no solo previamente preparado para recebê-los, de acordo com critérios técnico-construtivos e operacionais adequados, em consonância com as exigências dos órgãos ambientais competentes (PANDOLFO, 2005).
} 
cupações referentes à geração descontrolada de RCD é a disposição irregular. Normalmente os municípios não coletam o entulho gerado, sendo comuns os despejos clandestinos dos mesmos, em vias públicas, terrenos baldios, margens de rios, e ainda em bota-fora irregulares, que acabam se transformando muitas vezes em lixões.

Na visão de Pandolfo (2005), as deposições irregulares normalmente são resultado de pequenas obras ou reformas realizadas pelas camadas da população urbanas mais carentes de recursos, normalmente por processo de autoconstrução, porque não dispõem de recursos financeiros para a contratação das empresas coletoras.

$\mathrm{O}$ autor ainda afirma que com isso, diariamente, um dos problemas persistentes que as administrações municipais enfrentam é a remoção de resíduos, das mais diversas composições, não removidos pela coleta regular. Esses são descartados clandestinamente em todos os tipos de áreas, como terrenos públicos e particulares, vias de tráfego, passeios e áreas verdes, propiciando a proliferação de vetores, impedindo o tráfego de veículos e pedestres, enfim deteriorando a paisagem urbana.

As disposições irregulares dos RCD's causam impactos sociais e ambientais, como o comprometimento drenagem superficial e, consequentemente, o surgimento de enchentes; aumento da deposição de outros tipos de resíduos sólidos, para os quais também não são oferecidas soluções aos geradores; geração de depósitos instáveis que podem causar deslizamentos; criação de um ambiente propício para a proliferação de vetores prejudiciais às condições de saneamento e à saúde humana. (PINTO, 1999; SILVA, 2000).

$\mathrm{Na}$ opinião de Lopes (2006), quando os resíduos são descartados das construções, como material praticamente inerte, o entulho causa ônus e problemas associados ao seu volume, geralmente bastante significativo, chegando a ocupar em torno de $50 \%$ do volume total dos aterros públicos de algumas cidades brasileiras pesquisadas.

Ainda segundo a autora, embora a responsabilidade seja dos geradores, pela retirada desses resíduos das obras, a coleta e o transporte de RCD são atividades desenvolvidas por empresas coletoras de entulho, sem afetar a limpeza urbana das cidades. Para cumprirem as exigências legais de remoção das grandes quantidades de RCD que se acumulam durante as fases de obra, os geradores contratam empresas coletoras de entulho que, por meio de suas caçambas metálicas, estocam e transportam todos os resíduos produzidos até o local de disposição final.

No entanto, muitas vezes, essas empresas não descartam os resíduos coletados nas áreas definidas pelas prefeituras como aterros de inertes, em razão de alguns aspectos estruturais, como, por exemplo, a falta de fiscalização e controle das administrações municipais das atividades de coleta e transporte dos RCD; altos custos operacionais das empresas coletoras com combustíveis e manutenção da frota em razão das distâncias dos pontos geradores até os locais de disposição; falta de incentivos à triagem e ao beneficiamento dos RCD, o que transformaria os resíduos reciclados em novos materiais; falta de mercados para captação dos RCD, entre outros (SILVA, 2001).

Neste contexto, compete aos governos municipais administrar o manejo dos resíduos de construção e demolição, a fim de evitar seu descarte em áreas não regulamentadas, o que ocorre com frequência. Atualmente, o descarte ocorre em terrenos baldios ao longo de cursos d' água e em áreas periféricas, o que, além de causar danos ao meio ambiente, tem alto custo operacional de limpeza pública. Parte significativa desses resíduos depositados em áreas inadequadas agrava problemas urbanos como, por exemplo, enchentes e tráfego congestionado, como demonstrado por Colombo (1999 apud NETO, 2005).

Diante da situação de deposição dos resíduos nas cidades, o poder público municipal atua, frequentemente, com medidas paliativas, realizando serviços de coleta e arcando com os custos do transporte e disposição final. Tal prática, contudo, não soluciona definitivamente o problema de limpeza urbana, por não alcançar a remoção da totalidade dos resíduos, ao contrário, incentiva à continuidade da disposição irregular nos locais atendidos pela limpeza pública da administração municipal, segundo Pinto (1999).

Conforme Pandolfo (2005), para minimizar os impactos causados pelos RCD, nas diversas áreas de deposição clandestina, é preciso organizar um eficiente sistema de coleta e transporte com base em medidas que facilitem o descarte regular estabelecido pelas prefeituras. Nos termos da política nacional de resíduos sólidos, o RCD é de responsabilidade dos seus geradores.

De maneira geral, os municípios coletam tão somente os resíduos de construção civil lançados em logradouros públicos, independentemente da responsabilidade desses resíduos ser do gerador. É significativa à quantidade total de RCD coletada em 2010, que permite a constatação de que os municípios brasileiros coletaram 8,7\% a mais de RCD que em 2009 (ABRELPE, 2010).

A aplicação de um gerenciamento dos resíduos representa uma possibilidade de reduzir os impactos ambientais produzidos pelo setor, através da introdução de técnicas que visem à minimização da produção, reaproveitamento e a destinação correta dos RCD.

\section{Gestão Pública para Resultados}

O termo "gestão" indica planejar, organizar, liderar e controlar as pessoas que constituem uma organização e, consequentemente, as atividades pelas mesmas realizadas. Em relação aos RCD, a gestão como um todo está sendo iniciada como se fosse um aprendizado, e a indústria da construção civil brasileira já está dando os 
primeiros passos, como afirma Palermo (2006).

Gerenciamento integrado dos resíduos sólidos são atividades referentes à tomada de decisões estratégicas no que tange ao desenvolvimento, à implementação e à operação das ações definidas no Plano de Gestão Integrada de resíduos sólidos, da fiscalização e do controle dos serviços de manejo dos resíduos sólidos. Entretanto, essa gestão integrada pode ser entendida como a maneira de conceber, implementar e administrar sistemas de manejos de resíduos sólidos urbanos, considerando uma ampla participação dos setores da sociedade e tendo como perspectiva o desenvolvimento sustentável.

Na visão de Pereira et alii. (2013, p.84), a gestão integrada dos resíduos sólidos é estabelecida como:

\begin{abstract}
A tomada de decisões voltada aos resíduos sólidos de forma a considerar a dimensões políticas, econômicas, ambientais, culturais e sociais, considerando a ampla participação da sociedade, tendo como premissa o desenvolvimento sustentável. Pode se entender que a gestão dos resíduos sólidos compreende o planejamento das possíveis ações do gerenciamento. Antes, porém cabem os necessários diagnósticos da situação do gerenciamento do município, o levantamento das potencialidades, bem como a construção das parcerias para o planejamento.
\end{abstract}

Ou seja, todo o arcabouço legal e filosófico dos caminhos que busquem a minimização, tratamento e disposição dos resíduos sólidos são considerados como gestão dos resíduos sólidos como destaca o autor. Onde deve ser integrada pelas diversas dimensões que a questão permeia como os aspectos de saúde, de educação, de meio ambiente, sociais e econômicos. Compete então ao gerenciamento à implementação dessas decisões, buscando as alternativas técnicas, de acordo com a realidade local, a operação das ações propostas, a fiscalização e dimensionamento dos resultados dessas ações.

Gerenciar os resíduos de forma integrada é articular, ações normativas, operacionais, financeiras e de planejamento que uma administração municipal desenvolve, apoiada em critérios sanitários, ambientais e econômicos, para coletar, tratar e dispor o lixo de uma cidade, ou seja: é acompanhar de forma criteriosa todo o ciclo dos resíduos, da geração à disposição final, empregando as técnicas e tecnologias mais compatíveis com a realidade local.

A política brasileira para os Resíduos Sólidos identifica o desenvolvimento dos Planos de Gestão dos Resíduos Sólidos, em todos os níveis - incluindo Nacional e Estadual -, como a principal preocupação. A principal razão para esta ação é que os Planos de Gestão dos Resíduos Sólidos interagem com aspectos ambiental, econômico, legal entre outros, oferecendo um plano sistematizado para uma melhor implementação, tendo soluções disponíveis, tanto em termos de aceitação social quanto de viabilidade econômica (ABRELPE, 2010, p.4).

A Política Nacional de Resíduos Sólidos (2010) afirma:

[...] institui a responsabilidade compartilhada dos geradores de resíduos: dos fabricantes, importadores, distribuidores, comerciantes, o cidadão e titulares de serviços de manejo dos resíduos sólidos urbanos na logística reversa dos resíduos e embalagens pós-consumo e pós-venda. Cria metas significativas que irão contribuir para a eliminação dos lixões e institui instrumentos de planejamento nos níveis nacional, estadual, microrregional, intermunicipal e metropolitano e municipal; além de impor que os particulares elaborem seus Planos de Gerenciamento de Resíduos Sólidos (BRASIL, LEI 12.305/2010).

Para Monteiro et alii. (2001) a gestão integrada dos resíduos sólidos possui uma visão moderna que consiste na compreensão de diversos órgãos da administração pública e da sociedade civil com o desígnio de realizar a limpeza urbana, levando em consideração as características, econômicas e culturais dos cidadãos e as particularidades demográficas, climáticas e urbanísticas locais.

Nesse contexto, segundo o CEMPRE (2007), o plano de gerenciamento de resíduos sólidos é uma demonstração que evidencia o estado atual do sistema de limpeza urbana. Com a pré-seleção das possibilidades mais viáveis, e a implantações de ações integradas e diretrizes sob os aspectos ambientais, econômicos, financeiros, administrativos, técnicos, sociais e legais para todas as fases de gestão dos resíduos sólidos, desde a sua geração até a destinação final.

Os órgãos municipais brasileiros envolvidos com a questão dos RSU (resíduos sólidos urbanos) adotam basicamente dois modelos, um de gestão (político-administrativa) e outro de gerenciamento (manejo tecnológico) dos resíduos, segundo Lopes (2007). Nesse sentido, o modelo de Gestão de resíduos sólidos urbanos estabelece a forma pela qual se conduz politicamente a questão, enquanto o modelo de gerenciamento estabelece os critérios técnicos de tratamento e disposição final dos resíduos sólidos urbanos.

A responsabilidade quanto ao gerenciamento dos resíduos sólidos no país podem variar de acordo com sua origem, como, por exemplo, resíduos domiciliar, comercial e público é de responsabilidade da prefeitura. Já os resíduos industriais, serviços de saúde, portos, aeroportos, terminais ferroviários, resíduos agrícolas e entulhos são de responsabilidades do gerador de resíduos, tal como prevê a Política Nacional de Resíduos Sólidos (2004). 
As diretrizes especificadas pela Resolução CONAMA N ${ }^{\circ} 307 / 02$, que torna obrigatória a elaboração de um Plano Integrado de Gerenciamento de Resíduos da Construção Civil (PIGRCC) para todos os municípios e o distrito federal, estimularam o surgimento de leis e decretos municipais, para que todas as exigências contidas na resolução sejam cumpridas. Conforme a figura 2 , tendo em vistas as metas a serem alcançadas têm-se 4 ações fundamentais a serem adotadas.

Destaca-se que como a Resolução estabelece, as

Figura 2: Sistema de gestão para resíduos de construção e resíduos volumosos

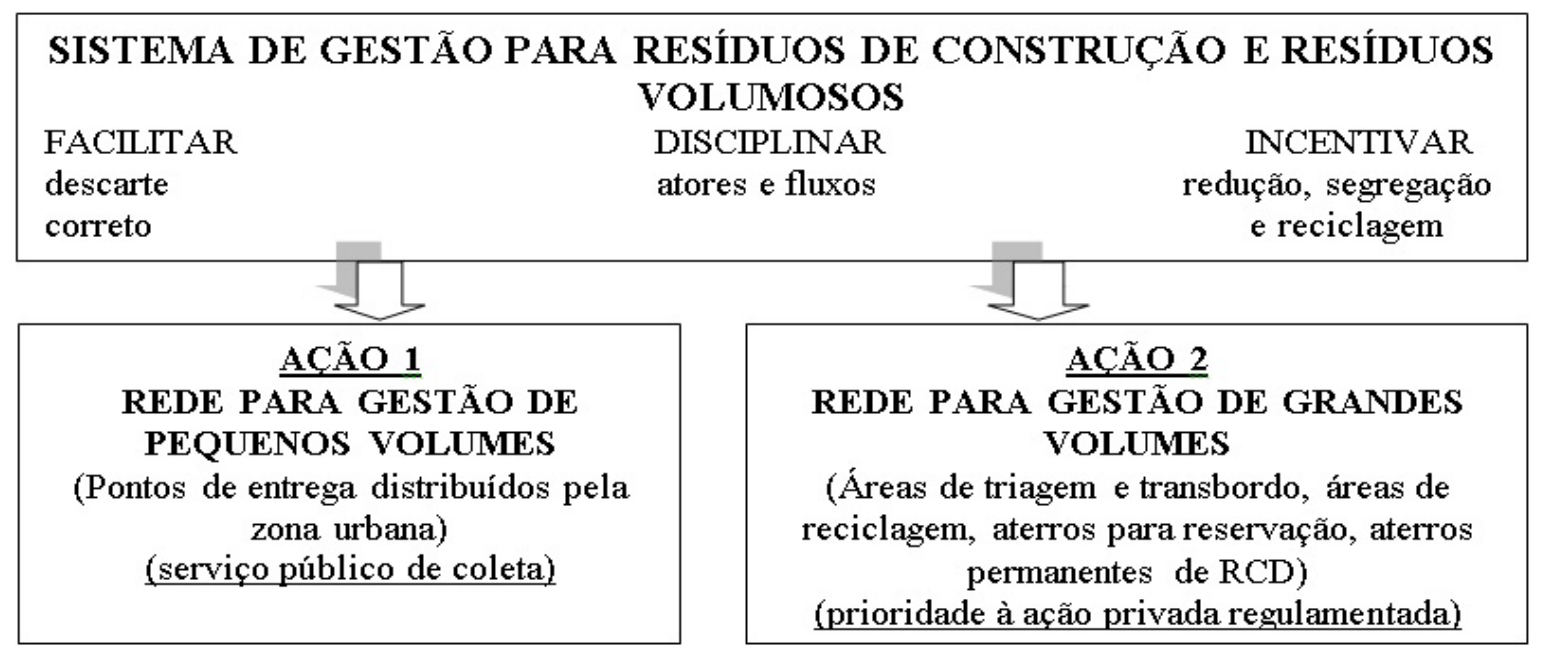

ACC̃OO 3_PROGRAMA DE INFORMÇÃO AMBIENTAL

ACÃO 4 PROGRAMA DE FISCALIZAÇÃO

Fonte: Adaptado de Pinto e Gonzáles (2005).

ações 1 e 2 devem abordadas na perspectiva de redes. Logo, devem ser implantadas duas redes de serviços, uma ancorada em pontos de entrega para os pequenos geradores das áreas mais periféricas e outra destinada aos grandes volumes, em que as empresas privadas de coleta possam recolher, transportar e dar a destinação adequadas a tais resíduos, na figura 3, está representada a articulação dessas redes de serviços de destinação dos RCD's.

Esta perspectiva é compartilhada por vários estudiosos do tema. Para Neto (2005), é fundamental a compreensão da gestão diferenciada dos RCD para que a mesma seja constituída por ações integradas que visam à captação máxima de RCD; o autor acredita que essas ações podem ser realizadas por meio de áreas de atração diferenciada para pequenos e grandes geradores ou coletoras, reciclagem dos resíduos captados em áreas especialmente definidas para beneficiamento, alteração cultural dos procedimentos quanto à intensidade da geração, à correção da coleta e da disposição e à possibilidade de reutilização dos resíduos reciclados.

Do mesmo modo Pinto (1999) afirma que os principais objetivos da gestão diferenciada seriam a redução dos custos municipais com limpeza pública, destinação final dos RCD e minimização dos impactos causados pelos entulhos.

0 mesmo autor define que, o descarte facilitado dos pequenos volumes de resíduos, disposição racional dos grandes volumes de RCD, preservação dos aterros de inertes com sustentabilidade do desenvolvimento, preservação ambiental por meio de redução dos impactos provenientes da deposição irregular, incentivo à captação, reciclagem e reutilização dos RCD nos ambientes urbanos, o que acaba por servir como um incentivo à redução da geração dos enormes volumes dos resíduos, por meio da conscientização ambiental e da redução de perdas.

Em consonância com essa ideia de gestão diferenciada, é fundamental que os geradores dos resíduos de construção e demolição passem a investir cada vez mais em novas tecnologias de construção, visando o melhor aproveitamento dos materiais. Uma alternativa viável, com a finalidade de reduzir o volume produzido de resíduo, seria a tentativa de implantação de usina de reciclagem de resíduos de construção civil, tal como afirma Lopes (2007).

A Resolução Conama № 307/02 trouxe importante regulação sobre o tema, na medida em que estabeleceu diretrizes, critérios e procedimentos para a gestão dos resíduos da construção civil, em seu Art. 10º , conforme a classificação dos resíduos:

[...] classe A: deverão ser reutilizados ou reciclados na forma de agregados, ou encaminhados a áreas de aterro de resíduos da construção civil, sendo disposto de modo a permitir a sua utilização ou reciclagem futura; [Exemplo de resíduos: componentes cerâmicos, argamassas, concretos e similares]; classe B: deverão ser reutilizados, 
reciclados ou encaminhados a áreas de armazenamento temporário, sendo disposto de modo a permitir a sua utilização ou reciclagem futura; [Exemplo de resíduos: plásticos, papel e papelão, metais, vidros e outros]; classe C: deverão ser armazenados, transportados ou destinados em conformidade com as normas técnicas especificas; [Exemplo de resíduos: gesso e outros]; classe D: deverão ser armazenados, transpor- tados, reutilizados e destinados em conformidade com as normas técnicas especificas. [Exemplo de resíduos: tintas, solventes e similares] (CONAMA, 2002, p. 3).

Além disso, fixou prazos para que os municípios apresentem um Plano de Gerenciamento Integrado de Resíduos de Construção Civil.

Segundo o PGIRCC, o município é o titular e deve ser o principal responsável por ações sobre o controle

Figura 3: Plano integrado de gerenciamento dos resíduos da construção civil.

\section{PLANO INTEGRADO DE GERENCLAMENTO DOS RESWUOS DA CONSTRUÇÃO CIVIL \\ (Resolução CONAMA n' 307)}

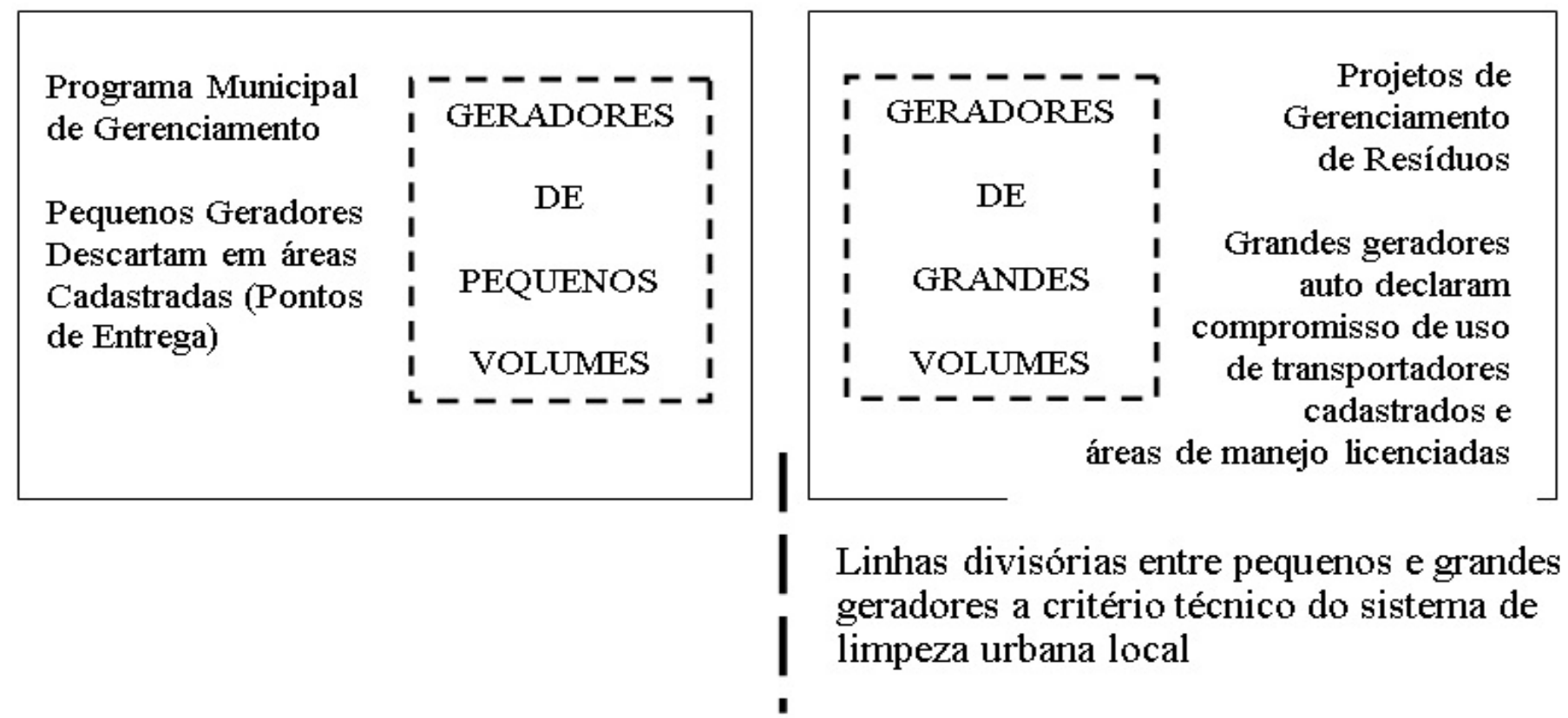

Fonte: Adaptado de Pinto e Gonzáles (2005).

do meio ambiente local. 0 poder público deverá promover, pelo manejo diferenciado e para reciclagem, a correção dos problemas ambientais decorrentes da disposição indiscriminada de resíduos da construção civil na malha urbana além de reduzir a quantidade de resíduos destinados para o aterro de inertes reintegrando-o ao ciclo produtivo.

É fundamental, ao se iniciar o plano de gerenciamento de resíduos da construção civil - PGRCC, que o dirigente municipal levante todas as legislações pertinentes a nível Federal, Estadual e Municipal sobre o assunto. As legislações Municipais podem ser encontradas na própria Lei Orgânica do Município, no Plano Diretor ou em outra legislação existente. No caso de verificar a insuficiência ou a inexistência das mesmas, caberá então, ao dirigente municipal encaminhamento ao jurídico para posteriores elaborações de tais necessidades.

A população deverá participar de forma organizada do processo da elaboração do PGRCC, no sentido de envolver o comprometimento e tornando-o assim, uma alternativa eficiente e irreversível (BOGADO, 1998). É sabido que a disposição dos resíduos da construção civil em locais inadequados contribui para contínua deterioração da qualidade ambiental. Diante disso, caberá ao município à responsabilidade do gerenciamento da disposição desses resíduos, criando legislações sobre o assunto de interesse local além de suplementar a legislação federal e a estadual quando couber.

Dessa forma, faz-se necessária a implantação de um gerenciamento bastante efetivo, contendo, inclusive, a não geração, separação e reciclagem dos resíduos nos próprios canteiros de obras, uma vez que a Resolução CONAMA no 307/2002:

[...] esclarece que "os geradores deverão ter como objetivo prioritário a não geração de resíduos e, secundariamente, a redução, a reutilização, a reciclagem e a destinação final". E estes resíduos "não poderão ser dispostos em aterros de resíduos domiciliares, 
em áreas de "bota fora", em encostas, corpos d'água, lotes vagos e em áreas protegidas por lei". As empresas têm, então, de gerenciar da melhor forma a destinação de todos os resíduos gerados na obra (PANDOLFO, 2005, p.120).

Para Russo (2003) a gestão de resíduos envolve uma inter-relação entre aspectos administrativos, financeiros, legais, de planejamento e de engenharia. Portanto, compreende-se que a gestão dos resíduos sólidos passa por vários pilares estruturantes que constituem uma política integrada, que se destaca pela adaptação dos sistemas integrados, baseada na redução na fonte, na reutilização de resíduos, na reciclagem, na transformação dos resíduos onde está incluída a incineração energética, a compostagem e a deposição em aterros.

Entretanto, segundo o autor, o âmbito desta abordagem em que os conceitos de gestão dos resíduos sólidos deverão seguir propostas para o equacionamento dos problemas destes resíduos, tendo como prioridades recomendações de prevenção, reutilização, recuperação, reciclagem, tratamento, disposição final, recuperação de áreas degradadas e ampliação da cobertura de serviços ligados aos resíduos.

Mesmo que vários Planos de GIRS - Gerenciamento Integrado dos Resíduos Sólidos, foram desenvolvidos em todo o mundo, não há regulamento correto de como realiza-los. Esta, eventualmente é uma das principais razões pelas quais os Planos de GIRS, em muitos casos, enfocam exclusivamente os problemas de GIRS, mas são incapazes de lidar com o problema global da gestão dos resíduos de maneira integrada e fracassam em prover soluções sustentáveis. Como consequência, os sistemas de GIRS que foram aplicados com sucesso em países desenvolvidos, podem não ter uso nos países em desenvolvimento, ou podem ter sucesso apenas sob certas condições (ABRELPE, 2010).

De tal modo, como define o "Panorama dos Resíduos Sólidos", o planejamento poderá definir as bases para a implantação e operação com alta qualidade da infraestrutura e dos sistemas de gestão de resíduos, que podem ser acessíveis para a sociedade e com tecnologias onde os recursos lo $\urcorner$ cais devem estar envolvidos. Por esta razão, especialmente em países em desenvol $\neg$ vimento, existe a necessidade de incluir boas práticas de planejamento na Gestão de Resíduos Sólidos (GRS), para criar planos de gestão realísticos e factíveis, e de acordo com eles, resolver o problema dos resíduos.

Seguir tais recomendações em conformidade com a realidade de cada localidade é fundamental, pois os espaços urbanos não suportam mais soluções emergenciais e não preventivas para impactos causados por resíduos de construção e demolição. A insustentabilidade da gestão corretiva e a ausência de gerenciamento em todo o processo gerador de RCD apontam a necessidade de novas políticas, estruturadas em es- tratégias sustentáveis e integradas com a administração municipal e a sociedade civil (CARNEIRO, 2005). Os problemas gerados pelos resíduos de construção e demolição nas cidades precisam ser reconhecidos e assumidos pelos gestores de limpeza pública, sendo que as soluções devem ser duráveis e ambientalmente adequadas, o que se torna possível também com contínuos monitoramento e fiscalização.

\section{Considerações Finais}

A produção de resíduos sólidos é crescente e a sua destinação, em muitos casos, em grande parte dos municípios brasileiros ainda é inadequada. Contudo, tem-se aumentado o conhecimento das implicações sobre o meio ambiente, bem como das ações para solucionar o problema.

Destacam-se os avanços, sobretudo em termos legais, a partir da Resolução CONAMA N³07/02, que deu início a uma série de atividades envolvendo a valorização dos RCD, pelo incentivo à reutilização, reciclagem e responsabilização dos geradores em relação à elaboração de programas de gerenciamento dos mesmos. E também a Lei Federal № 12.305/10, que institui a Política Nacional dos Resíduos Sólidos (PNRS), de modo que veio para assegurar as diretrizes relativas à gestão integrada e ao gerenciamento de resíduos sólidos (incluídos os RCD), bem como às responsabilidades dos geradores e do poder público e os instrumentos econômicos aplicáveis.

No plano prático, a partir da gestão do RCD e do envolvimento dos agentes sociais interessados, é possível se obter ganhos socioeconômicos significativos. No entanto, apesar de possuir uma legislação avançada, no Brasil, o processo de reciclagem e reaproveitamento dos RCD vem se ampliando lentamente, ainda não atendendo às necessidades do setor. É preciso maior fiscalização e participação dos órgãos públicos, sociedade e empresas da construção civil no que diz respeito ao destino dado aos RCD. Esta ação coletiva poderá evitar os despejos em locais inapropriados, garantir acessibilidade a locais adequados para sua disposição e reciclar e/ou reaproveitar esses resíduos. Sendo que o reaproveitamento e a reciclagem de matérias-primas contribuem para a geração de renda com inclusão social, assim como também minimiza o impacto ambiental causado pelo aterramento dos resíduos.

A aplicação da metodologia de gerenciamento desses resíduos de construção civil pode proporcionar vantagens significativas tanto às construtoras, como também ao meio ambiente. Nesse contexto, conforme Medeiros (2002), o surgimento de legislação específica, tanto no âmbito federal quanto no municipal, e de normas para o setor da construção civil, pode ser considerada como a principal responsável pelo surgimento de uma nova postura em relação aos RCD. Isso porque os agentes envolvidos, sentindo que novos padrões estão sendo estabelecidos, começam a mostrar interesse 
pelo assunto e, dessa forma, a procurar soluções que possam reduzir os problemas associados às atividades da construção civil.

\section{Referências}

ÂNGULO, S. C.; ZORDAN, S. E.; JOHN, V. M. Desenvolvimento Sustentável e Reciclagem de Resíduos na Construção Civil, 1999. Departamento de Engenharia Civil, Escola politécnica da Universidade de São Paulo. Disponível em: http:// www.reciclagem.pcc.usp.br/artigos.htm. Acesso em: 21 jan. 2014.

ASSOCIAÇÃO BRASILEIRA DE EMPRESAS DE LIMPEZA PÚBLICA E RESÍDUOS ESPECIAIS-ABRELPE. Panorama Nacional dos Resíduos Sólidos 2010. Disponível em: <http://www.abrelpe.org.br/panorama_envio. cfm?ano=2010 $>$. Acesso em: 19 nov. 2014.

ASSOCIAÇÃO BRASILEIRA DE NORMAS TÉCNICAS (ABNT). NBR 10.004:Resíduos Sólidos - Classificação. Rio de Janeiro, 2004. Disponível em:http://www. conhecer.org.br/download/RESIDUOS/leitura\%20 anexa\%206.pdf. Acesso em: 16 set. 2014.

BRASIL. Decreto-Lei no 12.305, de 2 de agosto de 2010. Institui a Política Nacional de Resíduos Sólidos; altera a Lei no 9.605, de 12 de fevereiro de 1998; e dá outras providências. Disponível em:<http://www.mma.gov.br/ port/conama/legiabre. cfm?codlegi=636>. Acesso em: 01 dez.2014.

CARNEIRO, F. P.. Diagnóstico e ações da atual situação dos resíduos de construção e demolição na cidade do Recife. Dissertação (Mestrado em Engenharia Urbana, Gerenciamento e Planejamento do Uso de Água e Resíduos) - Universidade Federal da Paraíba. João Pessoa - PB, 2005.

BOGADO, J. G. M.Aumento da produtividade e diminuição de desperdícios na construção civil: um estudo de caso - Paraguai. Dissertação (Mestrado), 1998. Universidade Federal de Santa Catarina (UFSC). Florianópolis, SC, 1998.

CASTILHO JR., A. B. Resíduos sólidos urbanos: aterro sustentável para municípios de pequeno porte. PROSAB, Florianópolis - SC, 2003.

CONSELHO NACIONAL DO MEIO AMBIENTE - CONAMA. Resolução no307 de cinco de julho de 2002. Dispõe sobre gestão dos resíduos da construção civil. Brasília, 2002. Disponível em: <http://www.mma.gov.br/port/ conama/res/res02/res30702.html>. Acesso em: 19 nov. 2013.

Compromisso Empresarial para Reciclagem - CEMPRE. Brasil: CEMPRE; 2006, 2007, 2010. Disponível em: <www.cempre.org.br>. Acesso em: 17 set. 2013.Resíduos sólidos: plano de gestão de resíduos sólidos urbanos: guia do profissional em treinamento: Nível dois. Belo Horizonte: ReCESA, 2007, p. 53.

DEMAJOROVIC, J. Da política tradicional de tratamento do lixo à política de gestão de resíduos sólidos: as novas prioridades.Revista de Administração de Empre- sas, São Paulo, v. 35, n. 3, p.88-93, jun. 1995.

FERNANDES, M. A. M. A. R. Processamento de Veículos em Fim de Vida e análise da viabilidade da reciclagem dos resíduos resultantes da sua fragmentação, 2009, 80 p. (Dissertação de mestrado em Ciências e Tecnologias do Ambiente), Universidade de Lisboa, Faculdade de Ciências, Lisboa, 2009.

FERREIRA, D. D. M. et alii. Gestão de resíduos da construção civil e de demolição; contribuições para a sustentabilidade ambiental. In: CONGRESSO NACIONAL DE EXCELENCIA EM GESTÃO, 5., 2009, Niterói, p. 1 - 23, jul., 2009. Disponível em: http://www.vcneg.org/documentos/anais_cneg5/T8_0139_0696.pdf. Acesso em: 24 mai.2014.

FIGUEIREDO; P. J. M. A sociedade do lixo: os resíduos, a questão energética e a crise ambiental. $2^{\text {a }}$ Edição. UNIMEP: Piracicaba, 1994. Disponível: <http://www.ichs. ufop.br/cadernosdehistoria/download/CadernosDeHistoria-04-14.pdf>. Acesso em: 22 out. 2013.

Instituto Brasileiro de Geografia e Estatística- IBGE. Pesquisa Nacional de Saneamento Básico. 2008. Disponível em: http://www.ibge.gov.br/home/estatistica/ populacao/condicaodevida/pnsb2008/. Acesso em: 24 mai.2014.

JACOBI, P. Impactos socioambientais urbanos: do risco à busca desustentabilidade. In: MENDONÇA, Francisco. (Org.).Impactos socioambientais urbanos. Curitiba: UFPR, 2004.

JACOBI, P. Gestão compartilhada dos resíduos sólidos no Brasil: inovação com inclusão social. São Paulo: Annablume, 2006.

JOHN, V. M. Reciclagem de resíduos na construção civil: contribuição à metodologia de pesquisa e desenvolvimento. Tese (Livre Docência em engenharia civil) - Escola Politécnica da Universidade de São Paulo, São Paulo: 2000.

LEVY, S. M.Reciclagem do entulho da construção civil para utilização como agregados para argamassas e concretos. Dissertação (mestrado) - Escola Politécnica, Universidade de São Paulo, São Paulo, 1997.

LOPES, L. Gestão e gerenciamento integrado de resíduos sólidos: alternativa para pequenos municípios. Dissertação de Mestrado. São Paulo: Programa de Pós-graduação em Geografia Humana (Universidade São Paulo), 2006.

LOPES, J. C. de J. Resíduos sólidos urbanos: consensos, conflitos e desafios na gestão institucional da Região Metropolitana de Curitiba - PR. Tese de Doutorado. Curitiba: Programa de Pós-graduação em Meio Ambiente e Desenvolvimento (UFPR), 2007.

MEDEIROS, F. Resíduos de construção: leis e projetos tentam solucionar odestino final do material que sobra nas obras. Revista: Qualidade na Construção, São Paulo, no 26, maio, 2002.

MENDES, T. A. etal.Parâmetros de uma pista experimental executada com entulho reciclado. Anais da $35^{\underline{a}}$ 
Reunião Anual de Pavimentação, 2004, Rio de Janeiro RJ, Brasil, 2004.

MONTEIRO J. H. P. et alii. Manual de gerenciamento integrado de resíduos sólidos. Rio de Janeiro: IBAM, 2001.

NAIME, H. R.; SPILKI, R. F.; Preservação ambiental e o caso especial do manejo de resíduos de laboratório: conceitos gerais e aplicados. Novo Hamburgo, Rio Grande do Sul: Feevale, 2012.

NETO, J. C. M. Gestão dos resíduos de construção e demolição no Brasil. São Carlos: Rima, 2005

PANDOLFO, A. et alii. Gestão diferenciada de resíduos da construção civil: uma abordagem ambiental. Porto Alegre: Edipucrs, 2005.

PALERMO, M. A. Gerenciamento ambiental integrado. São Paulo: Annablume, 2006.

PEREIRA, A. et alii. Logística reversa e sustentabilidade. São Paulo: CengageLearnig, 2013.

PINTO, T. P.Metodologia para a gestão diferenciada de resíduos sólidos da construção urbana. Tese (Doutorado) - Escola Politécnica da Universidade de São Paulo, São Paulo: 1999.

PINTO, C. M. R. Reciclagem e desenvolvimento sustentável no Brasil. Belo horizonte: Recóleo, 2009.

PINTO T. de P.;GONZÁLES J. L. R.Manejo e gestão de re- síduos da construção civil. Brasília : CAIXA, 2005.196 P.

RUSSO, M. A. T. Tratamento de resíduos sólidos. 2003. 196 f. Dissertação - Departamento de Engenharia Civil, Universidade de Coimbra, Coimbra, 2003.

SANTOS, E. C. G. Aplicação de resíduos de construção e demolição reciclados (RCD-R) em estruturas do solo reforçado. Dissertação (Mestrado em Geotecnia). Escola de Engenharia de São Carlos da Universidade de São Paulo. São Carlos: 2007.

SCHNEIDER, D. M. Deposições irregulares de resíduos da construção civil na cidade de São Paulo. Dissertação (Mestrado em Saúde Pública) - Universidade de São Paulo, 2003.

SILVA, V. G. Avaliação do desempenho ambiental de edifícios.Revista: Qualidade na Construção. São Paulo, 2000.

SILVA, V.G.ANTAC - Encontro nacional e I encontro latino americano sobre edificações e comunidades sustentáveis: uma proposta de discussão para o construbusiness brasileiro. São Paulo, 2001.

ZORDAN, S. E. A utilização do entulho como agregado na confecção do concreto. Dissertação (mestrado) - Faculdade de engenharia civil, Universidade Estadual de Campinas (UNICAMP), Campinas, 1997.

\title{
A SHORT DISCUSSION OF THE ROLE OF THE INTEGRATED MANAGEMENT OF THE CONSTRUCTION AND DEMOLITION WASTE (CDW) FOR TURNING THEM IN RESOURCES
}

\begin{abstract}
Due to population growth, especially in urban areas, the volume of solid waste has become a problem for contemporary society, since many cities still lack an adequate management of solid waste disposal services. Considering the expansion of cities, a significant increase in the volume of construction and demolition waste (CDW) can be observed, resulting either from demolition in processes of urban renewal or from new buildings. Popularly called "rubbish," such waste can result in social and environmental problems if it does not receive a proper treatment. The CONAMA Resolution №. 307/02 has initiated a series of activities involving the recovery of CDW by encouraging the reuse, recycling and the accountability of its producers in relation to the elaboration of management programs. This article discusses the management of solid waste, namely construction and demolition waste (CDW), taking into account the main legal instruments that deal with the issue, in particular the CONAMA resolution. For such, the literature available on this theme was reviewed. It is concluded that the application of the CDW management methodology can provide significant economic, social and environmental advantages. It is noteworthy also that the emergence of normative legal instruments, under different administrative scales, from federal to municipal, is a first step toward a new attitude concerning CDW, which should mainly be treated as resource and not as "trash."
\end{abstract}

Keywords: Solid waste. Construction and demolition waste. Management.

\section{BREVE ANÁLISIS DE LA FUNCIÓN DE LA GESTIÓN INTEGRADA DE LOS RESIDUOS DE CONSTRUCCIÓN Y DEMOLICIÓN (RCD) PARA CONVERTIR-LOS EN RECURSOS}

\footnotetext{
Resumen: Con el crecimiento de la población, especialmente en las zonas urbanas, la cantidad de residuos sólidos se ha convertido en un problema para la sociedad contemporánea, que aún carece de servicios de gestión de la eliminación de residuos sólidos en muchas ciudades. Teniendo en cuenta la expansión de las ciudades, ya sea por demoliciones en el proceso de renovación urbana, o por medio de nuevas construcciones, es significativo el aumento del volumen de los residuos de construcción y demolición (RCD). Popularmente denominados
} 
escombros, estos residuos pueden ocasionar problemas sociales y ambientales si no reciben el tratamiento apropriado. La Resolución CONAMA № 307/02 dio inicio a una serie de actividades que implican la valoración de la RCD, mediante el fomento del reuso, del reciclado y de la responsabilización de los generadores con respecto a la elaboración de programas de gestión de los RCD. El objetivo del presente artículo fue formular consideraciones sobre la gestión de residuos sólidos, sobre todo los residuos de construcción y demolición (RCD), tomando los principales instrumentos jurídicos que se refieren al tema, en particular la Resolución CONAMA. A esos efectos, se realizó una revisión bibliográfica para análisis de la cuestión. Se concluye que la aplicación de la metodología de gestión de los RCD puede proporcionar beneficios económicos, sociales y ambientales significativos. Es de destacar que el surgimiento de instrumentos jurídicos normativos legales, en las diferentes escalas administrativas, de la federal a la municipal, es una primera etapa para la emergencia de una nueva postura con relación a los RCD, que, en su mayoría, deben ser tratados como recursos y no como "basura".

Palabras Clave: Residuo Sólido. Residuos de construcción y demolición. Gestión. 